\title{
UNIVERSITAS ISLAM NEGERI (STUDI HISTORISITAS, PERKEMBANGAN DAN MODEL INTEGRASI KEILMUAN)
}

\author{
Rahmat Rifai Lubis
}

Sekolah Tinggi Agama Islam Sumatera Medan

Jl. Sambu No. 44/64 Kota Medan, Sumatera Utara

e-mail: pailubis8@gmail.com

\begin{abstract}
Abstrak: Penelitian ini bertujuan untuk menganalisis historisitas, perkembangan dan model integrasi kurikulum di Universitas Islam Negeri. Penelitian ini berjenis penelitian kualitatif degan pedekatan studi kepustakaan. Hasil penelitian menjelaskan bahwa UIN merupakan transformasi dari IAIN berdiri awal mula pada tahun 2002. perubahan IAIN menjadi UIN itu ada tiga tapap, yakni: (1) tahap Perintisan dan penjajagan yang dilakukan pada masa Harun Nasution sebagai rektor, (2) Tahap Pelanjutan dan pematangan konsep, tahap ini terjadi pada masa Quraish Shihab sebagai rektor, pada tahap ini disusun proposal perubahan IAIN menjadi UIN yang dikomandoi oleh Azyumardi Azra (3) Tahap pematangan gagasan dan implementasi. Sejak tahun 2002 (berdirinya Pertama kali UIN) hingga kini Perkembanga UIN mengalami kemajuan yang sangat pesat, Dari segi kuanitas, saat ini terdapat 23 UIN dari total 58 PTKIN atau sekitar $40 \%$ dari total perguruan tinggi Islam yang ada. Model integrasi keilmuan di UIN Syarif Hidayatullah ialah reintegrasi ilmu, UIN Sunan Ampel Surabaya konsep integrated twin towers (ITT), UIN Sumatera Utara mengusung Konsep Wahdatul Ulu, UIN Sunan Kalijaga konsep Integrasi Interkoneksi.
\end{abstract}

Kata Kunci: Universitas Islam Negeri, Integrasi Kurikulum, Pendidikan Tinggi

\begin{abstract}
This study aims to analyze the historicity, development and model of curriculum integration at the State Islamic University. This research is a qualitative research with a literature study approach. The results of the study explain that UIN is a transformation from IAIN which was first established in 2002. The change from IAIN to UIN has three stages, namely: (1) the Pioneering and exploratory stages which were carried out during Harun Nasution's time as Chancellor, (2) Continuation and maturation stages. concept, this stage occurred during the time of Quraish Shihab as rector, at this stage a proposal for changing IAIN to UIN was prepared which was led by Azyumardi Azra (3) The stage of maturation of ideas and implementation. Since 2002 (the first establishment of UIN) until now the development of UIN has progressed very rapidly. In terms of quantity, currently there are 23 UINs out of a total of 58 PTKIN or around $40 \%$ of the total existing Islamic universities. The scientific integration model at UIN Syarif Hidayatullah is the reintegration of knowledge, UIN Sunan Ampel Surabaya has the concept of integrated twin towers (ITT), UIN North Sumatra carries the Wahdatul Ulu concept, UIN Sunan Kalijaga has the concept of Interconnection Integration
\end{abstract}

Keywords: State Islamic University, Curriculum Integration, Higher Education 


\section{PENDAHULUAN}

Keberadaan Pendidikan tinggi Islam di Indonesia terus mengalami dinamika mengikuti perkembangan zaman. Dahulu lembaga pendidikan tinggi Islam hanya berbentuk sekolah tinggi agama dan Institut agama, kini berkembang menjadi universitas. Perubahan itu tentu tidak muncul begitu saja, akan tetapi atas dasar ragam alasan dan pertimbangan. Menurut Haidar Putra Daulay alasan utama tentu saja seiring dengan nama dan lingkup dari lembaga yang disebut dengan universitas. Jika disebut universitas maka lembaga tersebut menyelenggarakan pendidikan yang tidak hanya pada satu disiplin ilmu saja, akan tetapi ragam disiplin ilmu. Pendidikan Islam dalam konteks universitas diharapkan tidak hanya mengajarkan ilmu-ilmu agama saja, akan tetapi juga mengajarkan ilmu umum. Bahkan pada kekinian konteks universitas Islam hadir dalam tawaran integrase keilmuan. Dimana dalam Islam tidak dikenal adanya istilah dikotomi keilmuan, melainkan yang ada adalah kesatuan ilmu.

Secara tatakelola kelembagaan universitas tidaklah sama dengan lembaga pendidikan lain, Universitas merupakan Perguruan Tinggi yang menyelenggarakan pendidikan akademik dan dapat menyelenggarakan pendidikan vokasi dalam berbagai rumpun Ilmu Pengetahuan dan/atau Teknologi dan jika memenuhi syarat, universitas dapat menyelenggarakan pendidikan profesi. Institut merupakan Perguruan Tinggi yang menyelenggarakan pendidikan akademik dan dapat menyelenggarakan pendidikan vokasi dalam sejumlah rumpun Ilmu Pengetahuan dan/atau
Teknologi tertentu dan jika memenuhi syarat, institut dapat menyelenggarakan pendidikan profesi. Sedangkan sekolah Tinggi merupakan Perguruan Tinggi yang menyelenggarakan pendidikan akademik dan dapat menyelenggarakan pendidikan vokasi dalam satu rumpun Ilmu Pengetahuan dan/atau Teknologi tertentu dan jika memenuhi syarat, sekolah tinggi dapat menyelenggarakan pendidikan profesi. Ringkasnya universtas mencakup ragam ilmu, termasuk bisa saja di dalamnya memuat rumpun ilmu-ilmu agama.

Universitas Islam Negeri memang diharapkan menjadi wadah bagi berkembanganya model pendidikan Islam. Sehingga dapat dikenal oleh masyarakat luas, bahkan sampai dikenal oleh masyarakat dunia. Nyatanya memang saat ini terdapat banyak UIN di Indonesia yang telah berkontribusi dalam perkembangan pendidikan Islam di Indonesia. Konsep integrasi keilmuan yang dahulunya mungkin tertuang dalam bentuk konsep-konsep semata, kini mulai dipraktikkan pada lembaga pendidikan tinggi Islam di Indonesia, bahkan tidak menutup kemungkinan akan menjadi model bagi pendidikan tinggi Islam di dunia.

Konversi alih status dari IAIN ke UIN memang membutuhkan persyaratan yang cukup banyak, sehingga perubahan itu tidak dapat dilakukan dengan mudah begitu saja. Tidak cukup persyaratan administrasi saja, akan tetapi juga persyaratan substantif. Secara substantif tentu saja harus bertujuan untuk pengembangan ilmu pengetahuan, dan yang terpenting keberadaanya dapat sesuai dengan kebutuhan masyarakat. 
Hikmah, Vol. 18, No. 2, Juli-Desember 2021, p-ISSN: 1829-8419 e-ISSN: 2720-9040

Keberadaanya bukan hanya sekedar untuk menaikkan pamor atau gengsi lembaga pendidikan semata, jika itu yang terjadi justru tidak sesuai dengan yang dicitacitakan oleh para tokoh awal pendidikan Islam itu sendiri.

Oleh karena UIN merupakan produk dari dinamika pendidikan Islam, maka tentu jalan panjang keberadaanya tidak terlepas dari sejarah sosial yang melatarbelakanginya. dan tentu itu menjadi kunci untuk lebih memahami orientasi UIN itu kedepan, atau dengan kata lain agar dalam laju perkembangannya tidak berada pada koridor orientasi yang salah. Sebab perkembangan zaman yang ada saat ini tidak menutup kemungkinan itu dapat terjadi. Bahkan tidak hanya itu masuk dan berkembangnya ide-ide pemikiran pendidikan barat juga menjadi tantangan untuk tetap mempertahankan konsep integrasi pendidikan yang dikumandangkan di Universitas Islam Negeri.

Secara khusus penelitian ini akan membahas tentang sejarah lahirnya UIN, perkembangan UIN dan karekteristik keilmuan. Penelitian ini diharapkan dapat berkontribusi bagi pengembangan model kurikulum pendidikan pada lembaga pendidikan tinggi Islam, seperti sekolah tinggi ataupun institut keagamaan. Dengan adanya ini diharapkan pendidikan tinggi keagamaan dapat merubah pola keilmuannya, sehingga benar-benar menunjukkan jati diri keislaman.

\section{METODE PENELITIAN}

Penelitian ini berjenis penelitian kualitatif dengan menggunakan pendekatan studi kepustakaan. Penelitian ini menggunakan teknik dokumentasi dalam pengumpulan datanya, berbagai dokumen kepustakaan baik cetak dan elektronik dikumpulkan untuk mencapai tujuan Penelitian. Teknik analisa data menggunakan teknik analisis konten yakni menganalisis dokumen-dokumen yang menjadi rujukan. Dalam hal ini pengklasifiksian dokumen didasarkan pada pokok permasalahan yang telah ditentukan, lalu kemudian peneliti memberikan interpretasi terhadap temuan, dan mendeskripsikannya sehingga menjadi uraian penelitian.

Penelitian ini menganut dua corak penelitian, yakni corak sejarah dan corak kurikulum lembaga pendidikan. Keduanya menjadi ciri khas yang menonjol dalam penelitian ini, dan ini yang membuat penelitian ini berbeda dengan penelitianpenelitian sebelumnya, jika penelitian lain mungkin hanya terfokus pada sejarah lahir ataupun perkembangannya pada masa kini. Penelitian ini tidak lah demikian, namun mencoba untuk mengkombinasikan latar sejarah sosil dengan model karekteristik keilmuan yang ada saat ini.

\section{HASIL DAN PEMBAHASAN}

Pada awal pembahasan ini penulis sengaja untuk menjelaskn perbedaan ragam jenis lembaga pendidikan tinggi Islam, tujuannya untuk lebih memfokuskan pembahasan. Berdasarkan Undang-undang No. 12 tahun 2012 tentang Pendidikan Tinggi dikemukakan pengertian tiga bentuk perguruan tinggi, dan untuk lebih memeudahkan dalam memahami perbedaan 
tersebut, berikut diringkas perbedaanya dalam bentuk tabel:

\section{Tabel 1}

Perbedaan universitas, Institut, dan Sekolah tinggi keagamaan

\begin{tabular}{|c|c|c|}
\hline Universitas & Institut & $\begin{array}{c}\text { Sekolah } \\
\text { tinggi }\end{array}$ \\
\hline $\begin{array}{l}\text { Menyelenggarak } \\
\text { an pendidikan } \\
\text { akademik dan } \\
\text { dapat } \\
\text { menyelenggarak } \\
\text { an pendidikan } \\
\text { vokasi }\end{array}$ & $\begin{array}{l}\text { Menyelenggarak } \\
\text { an pendidikan } \\
\text { akademik dan } \\
\text { dapat } \\
\text { menyelenggaraka } \\
\text { n pendidikan } \\
\text { vokasi }\end{array}$ & $\begin{array}{l}\text { Menyelenggara } \\
\text { k-an } \\
\text { pendidikan } \\
\text { akademik dan } \\
\text { dapat } \\
\text { menyelenggara } \\
\text { kan pendidikan } \\
\text { vokasi }\end{array}$ \\
\hline $\begin{array}{l}\text { Terdiri dari } \\
\text { berbagai rumpun } \\
\text { Ilmu } \\
\text { Pengetahuan } \\
\text { dan/atau } \\
\text { Teknologi }\end{array}$ & $\begin{array}{l}\text { Terdiri sejumlah } \\
\text { rumpun ilmu } \\
\text { pengetahuan } \\
\text { dan/atau } \\
\text { teknologi } \\
\text { tertentu (sejenis) }\end{array}$ & $\begin{array}{l}\text { satu rumpun } \\
\text { ilmu saja }\end{array}$ \\
\hline $\begin{array}{l}\text { Memiliki banyak } \\
\text { fakultas }\end{array}$ & & $\begin{array}{l}\text { Terdiri } \\
\text { beberapa } \\
\text { Jurusan }\end{array}$ \\
\hline $\begin{array}{l}\text { Beberapa } \\
\text { fakultas dengan } \\
\text { ragam keilmuan }\end{array}$ & $\begin{array}{l}\text { Beberapa } \\
\text { Fakultas berasal } \\
\text { dari satu } \\
\text { keilmuan saja }\end{array}$ & $\begin{array}{l}\text { Jurusan- } \\
\text { jurusan pada } \\
\text { satu fakultas } \\
\text { keilmuan. }\end{array}$ \\
\hline $\begin{array}{l}\text { Contoh: } \\
\text { Fakultas } \\
\text { Kedokteran, } \\
\text { Fakultas teknik, } \\
\text { Fakultas agama } \\
\text { Islam dan } \\
\text { humaniora, } \\
\text { Fakultas } \\
\text { hukum,Dll. }\end{array}$ & $\begin{array}{l}\text { Contoh: } \\
\text { Fakultas } \\
\text { Tarbiyah, } \\
\text { Fakultas Syariah, } \\
\text { Fakultas dakwah } \\
\text { (beberapa } \\
\text { rumpun tapi } \\
\text { dalam satu } \\
\text { keilmuan agama) }\end{array}$ & $\begin{array}{l}\text { Contoh: } \\
\text { Jurusan PAI, } \\
\text { Jurusan PGMI, } \\
\text { BKI, PIAUD, } \\
\text { Ekonomi } \\
\text { syariah. } \\
\text { (Semuanya } \\
\text { satu rumpun } \\
\text { ilmu } \\
\text { keagamaan } \\
\text { saja) }\end{array}$ \\
\hline
\end{tabular}

\section{Sejarah Lahirnya Perguruan Tinggi Islam di Indonesia}

Sebenarnya

umat Islam untuk gagasan

mendirikan lembaga tinggi sudah dirintis sejak zaman kolonial Belanda. Gagasan umat Islam untuk mendirikan perguruan tinggi berawal dari kenyataan yang ada di Indonesia bahwa umat Islam jauh tertinggal di bidang pendidikan. Sistem pendidikan di madrasah maupun pesantren lebih menekankan ilmu-ilmu agama tidak dapat dipertahankan untuk mengahadapi kemodrenan masyarakat maupun persaingan dengan sistem pendidikan yang dilaksanakan oleh Pemerintah kolonial Belanda. Sebab pada tahun 1920-an telah berdiri lembaga pendidikan tinggi milik pemerintah Belanda, yaitu Sekolah Tinggi Teknik yang sekarang menjadi Institut Tegnologi Bandung (ITB), pada tahun 1924 berdiri Sekolah Tinggi Hukum di Jakarta, dan tahun 1927 berdiri Sekolah Tinggi Kedokteran di Jakarta. Mahasiswa yang terdaftar di lembagalembaga yang didirikan oleh Belanda adalah berkebangsaan Indonesia,tetapi dari kalangan elit (priyai). Sedangkan bagi rakyat Indonesia dari kalangan rendah tidak memiliki kesempatan untuk belajar di lembaga itu. (Amiruddin, 2017)

Melihat keadaan ini, timbullah keinginan umat Islam untuk mendirikan Perguruan Tinggi Islam (PTI), sebuah pendidikan tinggi yang akan menampung kaum muslimin dari kalangan rendah. Tujuannya bukan saja ingin menampung calon-calon mahasiswa dari kalangan pribumi, melainkan juga menegaskan corak keislaman yang membedakannya dengan corak pendidikan kolonial Belanda yang hanya mementingkan pendidikan umum.

Hal yang hampir sama dikatakan oleh Pairin bahwa keberadaan pendidikan tinggi Islam pada dasarnya didorong oleh dua faktor. Pertama, faktor intern yaitu di Indonesia telah berdiri perguruan tinggi umum seperti sekolah tinggi teknik di bandung tahun 1920, sekolah tinggi hukum di Jakarta pada tahun 1920, dan sekolah tinggi ilmu kedokteran di Jakarta pada tahun 1927. Kedua, faktor ekstern yaitu respon atas kebutuhan masyarakat untuk merealisasikan 
Hikmah, Vol. 18, No. 2, Juli-Desember 2021， p-ISSN: 1829-8419 e-ISSN: 2720-9040

kehidupan beragama di tanah air dan masuknya ide-ide pembaharuan pemikiran Islam ke Indonesia. (Pairin, 2012).

Menurut Haidar Putra Daulay keinginan untuk mendirikan pendidikan tinggi Islam sudah ada sejak zaman penjajahan belanda (Daulay, 2018), beberapa bukti sejarahnya sebagai berikut:

a. Seperti yang dikemukakan oleh Dr. Satiman dalam catatannya beliau menulis didalam PM (Pedoman Masyarakat) Nomor 15 bahwa keinginannya mendirikan sekolah tinggi Islam yang akan didirikan di Jakarta, Solo dan Surabaya. Di jakarta rencananya akan diadakan sekolah tinggi sebagai bagian atas sekolah Menengah Muhammadiyah yang bersifat kebaratan, di Solo direncanakan pendidikan tinggi untuk mendidik muballigin, dan di Surabaya direncanakan sekolah tinggi untuk mereka yang berasal dari pesantren. Intinya hal tersebut masih terbatas ide yang kemunculannya itu diperkirakan sekitar tahun 1930-an. (Pairin, 2012).

b. Keterangan Muhammad Yunus bahwa pada tanggal 9 Desember 1940 sudah berdiri lembaga pendidikan tinggi Islam yang dipelopori oleh Persatuan Guru Agama Islam (PGAI), yang menurutnya juga ini merupakan lembaga pendidikan pertama di Sumatera Barat sekaligus di Indonesia. Saat itu memiliki dua fakultas yakni Fakultas Syariat, dan Fakultas pendidikan dan Bahasa Arab. Namun sayangnya ketika pada tahun 1941 jepang memasuki Wilayah Sumatera Barat pendidikan tinggi tersebut ditutup sebab jepang hanya mengizinkan dibuka tingkat dasar dan menengah.

c. Catatan lain menunjukkan bahwa semangat untuk mendirikan pendidikan tinggi Islam ini juga di bahas pada kongres II Majelis Islam 'Ala Indonesia (MIAI) yang berlangsung tanggal 2-7 Mei 1939 dalam salah satu agendanya adalah tentang Perguruan Tinggi Islam, akhirnya merealisasikan pendirian Perguruan Tinggi Islam di Solo yang dimulai dari tingkat menengah dengan nama Islamische Midel bare School (IMS).

Berdasarkan catatan sejarah tersebut dapat ditegaskan bahwa sejak masa colonial belanda cita-cita mendirikan pendidikan tinggi sudah ada. Namun perlu di tegaskan juga bahwa lembaga pendidikan tinggi umum pada rentang masa itu sudah berdiri, seperti Sekolah Tinggi Teknik yang sekarang menjadi Institut Teknologi Bandung (ITB), pada tahun 1924 berdiri Sekolah Tinggi Hukum di Jakarta, dan tahun 1927 berdiri Sekolah Tinggi Kedokteran di Jakarta.

Kembali dijelaskan oleh Haidar Putra Daulay bahwa berdirinya Perguruan tinggi oleh kolonial Belanda tersebut tentu diperuntukkan bagi masyarkat elit bangsa 
Indonesia. Atas dasar itulah maka mendorong para tokoh-tokoh penddikan Islam untuk mendirikan lembaga pendidikan tinggi Islam. Selama ini lembaga pendidikan Islam yang tersebar di wilayah Indonesia sangat demokratis dalam arti memberikan kesempatan yang sama untuk dapat mengenyam pendidikan. Perguruan tinggi Islam juga diprakarsai berdiri untuk menghilangkan sekat tersebut. (Daulay, 2019).

Usaha tersebut ternyata tidak putus sampai disitu, Masyumi (Majelis Syura Muslimin Indonesia) yang merupakan gabungan dari beberapa organisasi Islam, memplopori lahirnya Sekolah tinggi Islam (STI). Hal itu bermula dari diadakannya rapat di Jakarta pada bulan April 1945, yang di hadiri oleh beberapa tokoh di antaraya:

- PBNU yaitu K.H. Abdul Wahab, K.H. Bisri Syamsuri, K.H. Wahid Hasyim, K.H. Masykur dan Zainal Arifin.

- PB Muhammadiyah yaitu Ki Bagus Hadikusumo, K.H. Mas Mansyur, K.H. Hasyim, K.H. Farid Ma'ruf, K.H. Mu'thi, K.H. M. Yunus Anis, dan Kerto Sudarmo.

- $\quad$ PB Perserikatan Oemat Islam (POI) yaitu K.H. A. Halim dan H. Mansur.

- PB persatuan Umat Islam (PUI) yaitu A Sanusi dan Sumoatmojo.

- PB Al-Islam yaitu K.H. Imam Ghazali.

- Shumubu yaitu A. Kahar Muzakir, K.H. A. Moh. Adnan, K.H. Imam Zarkasi.

Hasil sidang memtuskan bahwa terbentuknya panitia untuk perencana berdirinya Sekolah Tinggi Islam yang dipimpin oleh Moh. Hatta dan Sekretarisnya M. Natsir, dan atas bantuan pemerinthah Jepang STI di buka resmi pada tangal 8 Juli 1945. Kurikulum yang digunakan mengikuti fakultas Ushuluddin Universitas Al-Azhar Kairo. Kemuadian pada masa kemerdekaan, yang kemudian di ikuti dengan munculnya agrsi militer belanda terjadi perubahan ibukota negara dari Jakarta ke Yogyakarta, maka dengan itu pindah pula lah STI ke Yogyakarta tersebut.

10 April 1946 STI juga pindah dan dibuka di Yogyakarta dan untuk meningkatkan efektivitas serta keluasan jaungkauan STI, maka muncullah pemikiran untuk memperbaiki dan mengembangkan STI, panitianya terdiri dari Fathurrahman, Kafrawi, Farid Ma'ruf, Kahar Mudzakkir, keputusan utamanya mengubah STI menjadi UII yang diresmikan pada 10 Maret 1948 dengan membuka empat Fakultas yaitu, Agama, Hukum, Pendidikan, dan Ekonomi.

Ketika UII berdiri, ecara otomatis STI tidak ada lagi dalam bentuk perguruan tinggi, sebab namanya diganti menjadi UII. UII sebagai universitas masih tetap eksis sampai saat ini dan masih beroperasional. Namun UII bukanlah universitas Negeri seperti PTAIN, ADIA, IAIN, STAIN dan UIN. UII tidak dikelola oleh pemerintah, baik kelembagaan maupun manajemen. UII berstatus swasta bukan negeri. Kontribusi UII terhadap kemunculan perguruan tinggi Islam di Indonesia begitu besar dalam pengembangan pendidikan Islam. Menurut Mahmud Yunus, setelah fakultas Agama UII dijadikan PTAIN oleh Pemerintah, maka UII hanya memiliki fakultas Hukum, Ekonomi, 
Hikmah, Vol. 18, No. 2, Juli-Desember 2021， p-ISSN: 1829-8419 e-ISSN: 2720-9040

dan Pendidikan (paedagogik). Kemudian, fakultas pendidikan terpaksa ditutup, karena kekurangan dosen-dosen, sehingga tinggal dua fakultas yakni fakultas Hukum dan Ekonomi. Fakultas Hukum ada dua buah: satu di Yogyakarta dan satu lagi di Solo (Surakarta).(Ikhwan, 2016).

Pada tanggal 22 Januari 1950, sejumlah pemimpin Islam dan para ulama juga mendirikan sebuah universitas Islam di Solo. Pada tahun itu juga, Fakultas agama yang semula ada di Universitas Islam Indonesia Yogyakarta diserahkan ke pemerintah, yakni Kementerian Agama dan kemudian dijadikan Perguruan Tinggi Agama Islam Negeri untuk golongan Islam yang diambil dari Fakultas Agama UII berdasarkan Peraturan Pemerintah No. 34 Tahun 1950. Penetapan PTAIN sebagai perguruan tinggi negeri diresmikan pada tanggal 26 September 1951 dengan jurusan Da'wah (kelak Ushuluddin), Qodla (kelak menjadi Syari'ah) dan Pendidikan (Tarbiyah). PTAIN didirikan di Yogyakarta pada tahun 1951 dengan peraturan pemerintah No.34 tahun 1950 dan ditandatangani oleh Presiden Republik Indonesia tanggal 14 Agustus 1950. (Fadriati, 2018).

Disamping PTAIN sebagai milik bersama Departemen Agama dan Departemen Pendidikan, Pengajaran dan Kebudayaan didirikanlah Akademi Dinas Ilmu Agama (ADIA) di Jakarta dengan penetapan Menteri Agama No.1 Tahun 1957. Adapun tujuan ADIA tersebut sebagai sambungan dari usaha mendirikan Pendidikan Guru Agama Atas (PGAA) dan Sekolah Guru dan Hakim Agama (SGHA).
Akademi Dinas Ilmu Agama bertujuan mendidik dan mempersiapkan pegawai negeri untuk mencapai ijazah semi akademi dan akademi untuk dijadikan ahli didik agama pada sekolah-sekolah lanjutan, baik umum maupun agama dan kejuruan.

Pada tahun 1957, di Jakarta didirikan Akademi Dinas Ilmu Agama (ADIA). Akademi ini bertujuan sebagai sekolah latihan bagi para pejabat yang berdinas di Pemerintahan (Kementerian Agama) dan untuk pengajaran agama di sekolah. Lama studi di ADIA 5 tahun yang terdiri dari dua tingkat yaitu; tingkat semi akademi 3 tahun dan tingkat akademi 2 tahun. Tiap-tiap tingkat memiliki dua jurusan: jurusan pendidikan Agama dan Jurusan sastra. ADIA di tujukan untuk meningkatkan kualitas pegawai negeri dalam bidang Keagamaan. ADIA terbuka hanya bagi pegawai-pegawai negeri. Setiap tahun atas usul kepala Jawatan Pendidikan Agama ditunjuk oleh Menteri Agama sejumlah pegawai negeri, supaya dengan tugas belajar mengikuti pendidikan pada Akademi itu.

Pada tanggal 26 september 1959, bertepatan dengan ulang tahun PTAIN, dibentuklah panitia perbaikan Perguruan Tinggi Agama Islam berdasarkan ketetapan menteri agama nomor 41 tahun 1959 yang dipimpin oleh Prof. Mr. R.H.A. Soenarjo. Hasil dari pada sidang panitia tersebut adalah PTAIN yang berada di Yogyakarta dengan ADIA (Akademi Dinas Ilmu Agama) yang berada di Jakarta digabungkan menjadi IAIN (Institut Agama Islam Negeri) Al-Jami'ah alIslamiyah al-Hukumiyah. Dan pemerintah menyetujui hasil rapat tersebut, maka itulah IAIN yang pertama kali ada di Indonesia. 
Ditandai dengan keluarnya Peraturan Presiden Republik Indonesia pada tanggal 9 mei 1960. IAIN pertama dibuka secara resmi di Yogyakarta pada tanggal 24 Agustus 1960 oleh Menteri Agama RI yaitu K.H. Wahid Wahab, pada tahap awal IAIN terdiri dari beberapa fakultas; fakultas Ushuluddin, Syari'ah, Tarbiyah dan Fakultas Adab.(Rifai et al., 2014).

Seiring dengan berjalannya waktu perkembangan IAIN Yogyakarta semakin meningkat, hal ini ditandai dengan berdirinya 16 fakultas di beberapa daerah/ wilayah Indonesia seperti Banda Aceh, Padang, Jambi, Palembang, Surabaya, dan lain-lain. Maka setelah itu fakultas-fakultas tersebut juga berkembang pesat. Sehingga untuk mengkoordinasikan hal tersebut digantilah peraturan presiden nomor 11 tahun 1960 menjadi peraturan presiden nomor 27 tahun 1963, yang berisikan tentang pembentukan IAIN di luar Yogyakarta di setiap daerah dengan syarat minimal adanya 3 fakultas untuk membentuk satu/berdirinya satu IAIN. Maka setelah itu akhirnya muncullah IAIN yang berada diluar daerah Yogyakarta dan Jakarta, dan pada tahun 1973 sudah ada 15 IAIN yang berada dibeberapa daerah Nusantara. (Rapono, 2020).

Upaya perbaikan dan pengembangan IAIN banyak dilakukan pada masa HA. Mukti Ali Menjadi menteri Agama, di antara yang dilakukannya dilakukan perbaikan yang dituangkan dalam garis-garis besar pembinaan IAIN yang meliputi 7 bidang yakni Organisasi, kurikulum, personil, materil, pembiayaan, penelitian, dan kemahasiswaan. Perkembangan selanjutnya pada tahun 1982 IAIN Jakarta dan 1983 IAIN Yogyakarta membuka program Pascasarjana S2 dan S3. (Minhaji, 2007).

$$
\text { Keberadaan IAIN memang }
$$

berkembang begitu pesat, dan disambut baik oleh masyarakat Indonesia. Sehingga pada waktu itu terlihat adanya cabang-cabang IAIN di luar dari Cabang induknya. Perkembangan selanjutnya menunjukkan tuntutan agar IAIN tersebut berdiri sendiri, dan pada tahun 1973 sudah terdapat 14 IAIN di seluruh Indonesia. Menurut Haidar IAIN yang telah berdiri tersebut, berdasarkan kebutuhan di berbagai daerah akhirnya membuka cabang-cabang di luar IAIN induknya, sehingga pada perkembangan berikutnya tidak dapat terhindarkan munculnya duplikasi fakultas, atas dasar itu lah maka cabang-cabang fakultas itu berdiri sendiri dengan nama STAIN. (Hanifah, 2018).

Setelah IAIN, seiring dengan itu berkembanglah IAIN tersebut menjadi UIN, karena perkembangan ilmu pengetahuan, maka tidak cukup hanya ilmu-ilmu yang berkaitan dengan keagamaan saja, tetapi dengan perkembangan zaman dan persaingan ketat dengan beberapa perguruan tinggi maka IAIN akhirnya berubah menjadi UIN dengan pengintegrasian ilmu-ilmu keagamaan dengan ilmu-ilmu non keagamaan. Maka yang pertama kali muncul adalah UIN Syarif Hidayatulloh di Jakarta pada tahun 2002 dan diikuti oleh lima IAIN lainnya dan satu STAIN. (Hasan, 2016).

Universitas Islam Negeri (UIN) merupakan lembaga perguruan tinggi Islam yang berbentuk Universitas. Sebelumnya dalam konstelasi PTKIN di Indonesia 
Hikmah, Vol. 18, No. 2, Juli-Desember 2021， p-ISSN: 1829-8419 e-ISSN: 2720-9040

memang ada Universitas, akan tetapi dalam bentuk swasta yakni UII (Universitas Islam Indonesia). Perguruan tinggi ini sudah lama terbentuk di Indonesia. Jika kemudian lahir Universitas Islam Negeri (UIN), sebetulnya bukanlah sesuatu yang langka dan baru. Justeru UII menjadi inspirasi atas kelahiran UIN, meskipun salah satu faktor, disamping faktor-faktor lain yang melatarbelakangi kelahiran UIN. Setidaknya, Universitas Islam sudah pernah digagas sebelumnya. Hal senada juga dikatakan Badri Yatim, Universitas Islam Indonesia (UII) adalah perguruan tinggi pertama yang memiliki fakultas-fakultas non agama. Dengan demikian, ia dapat memberi contoh tentang perkembangan universitas-universitas Islam di Indonesia.(Amiruddin, 2017).

\section{Tinjauan Sejarah Sosial Latar Belakang Lahirnya UIN}

Sub bahasan ini sengaja dipisahkan dari pembahasan historisitas perguruan tinggi secara umum dengan tujuan agar lebih memfokuskan kajian pada aspek sejarah sosialnya. Di tinjau dari segi sejarah sosialnya gagasan transformasi IAIN menjadi UIN pertama kali dikemukakan oleh Rektor IAIN Jakarta periode 1973-1984, yakni Prof. Harun Nasution. alasan Harun Nasution ingin mengembangkan IAIN menjadi UIN dikemukakan dalam sebuah wawancara dengan Republika, pada Kamis, 28 Desember 1995. Saat itu ia sudah menjadi Direktur Program Pascasarjana. "Kita merasa yang diperlukan umat di zaman sekarang ini bukan hanya sarjana yang mengetahui ilmu agama saja, tapi juga ilmu umum. Harus diakui tidak banyak orang yang bisa menguasai keduanya secara mumpuni. Hanya orang-orang jenius saja yang bisa melakukannya".(Chailani, 2019)

Berangkat dari kebutuhan itu, Harun berpendapat, IAIN perlu ditransformasikan menjadi universitas, sehingga dapat membuka jurusan-jurusan umum. Harapannya tentu saja mampu mencetak sarjana yang memiliki kompetensi agama namun tidak asing dengan pengetahuan umum. Hal itu bagi Harun bukan mustahi. Sejarah mencatat seorang Ibnu Rusyd dan Ibnu Sina yang selain ahli filsafat, syariah, juga seorang dokter yang masyhur. "Kalau pada masa lampau mereka bisa menghasilkan tokoh seperti itu, kenapa kita tidak mampu menghasilkannya. Inilah dasar pendirian kita sehingga ada keinginan untuk mengubah IAIN menjadi UIN," tegas Harun. (Suradi, 2018).

Kepastian pendirian UIN kian menunjukkan kejelasan setelah diadakannya Sarasehan di IAIN Jakarta pada 22 Oktober 1994. Sarasehan itu dihadiri oleh beberapa narasumber ternama, baik dari kalangan internal IAIN Jakarta dan kalangan luar. Dari Kalangan internal yakni Quraish Shihab (saat itu menjabat Rektor), Harun Nasution, Zakiah Drajat. Dari Luar yakni mewakili Departemen Agama ialah Atho Mudzhar, Perguruan tinggi Umum seperri Asri Rasyad dari Yayasan Rumah Sakit Islam Indonesia. Hanna Djumhana Bustaman dan Laode M Kamaluddin dari Universitas Indonesia (UI), dan Ahmad Baiquni dari badan Pengkajian dan Penerapan Teknologi (BPPT). Sarasehan itu kemudian membuahkan hasil berupa Departemen Agama menetapkan IAIN Jakarta sebagai pilot project dan 
mengharapkan agar upaya konversi IAIN menjadi UIN di awali dengan studi kelayakan beberapa hal yakni pengembangan kelembagaan, pengembangan ketenagaan, pengembangan kurikulum, pengembangan perpustakaan, pengembangan sarana dan prasarana, dan penyusunan RIP UIN. Proses ini semua terjadi pada masa kepemimpinan Rektor IAIN M. Quraish Shihab (19921998). Cita-cita tersebut akhirnya terealisasi pada 20 Mei 2002 pada masa periode kepemimpinan Rektor Azyumardi Azra (1998-2006). Setelah berganti nama, infrastruktur segera dibangun dan arah pengembangan diperjelas yakni menjadi universitas riset dan universitas kelas dunia. (Daulay \& Tobroni, 2017).

Jika bisa lebih diringkas lagi maka jalan perubahan IAIN menjadi UIN itu ada tiga tapap, yakni: (1) tahap Perintisan dan penjajagan yang dilakukan pada masa Harun Nasution sebagai rektor, (2) Tahap Pelanjutan dan pematangan Konsep, tahap ini terjadi pada masa Quraish Shihab sebagai rektor, pada tahap ini disusun proposal perubahan IAIN menjadi UIN yang dikomandoi oleh Azyumardi Azra sebagai pembantu Bidang Akademik. (3) Tahap pematangan gagasan dan implementasi. Tahap ini terjadi pada masa Azyumardi Azra sebagai rector. Proposal yang telah disusun kemudian dipresentasikan di hadapan senat, dan dilakukan juga upaya untuk terus beraudiensi baik kepada DPR, Sekretariat negara, Departemen pendayagunaan Aparatur Negara. Namun pada masa itu Sejarah membutktikan bahwa sempat terjadi ganjalan yakni aturan yang termuat dalam Peraturan Pemerintah Nomor 60 tahun 1999 tentang perguruan tinggi yang berada dibawah departemen non-kependidikan (Diknas), hanya dapat menyelenggarakan pendidikan tinggisampai dengan bentuk institut. Sedangkan untuk perguruan tinggi setingkat universitas harusberada di bawah naungan Diknas. Keadaan ini menimbulkan pro kontra, tentang apakah denganperubahan IAIN menjadi UIN tersebut pengelolaannya berpindah dari Departemen Agama kepada Departemen Pendidikan Nasional, ataukah tetap berada di bawah pengelolaan Departemen Agama. Upaya tarik menarik ini akhirnya dapat diselesaikan melalui kompromi dalam bentuk dikeluarkannya Surat Keputusan Bersama antara Menteri Agama RI dengan Menteri Pendidikan Nasional. Di dalam SKB tersebut dinyatakan bahwa secara kelembagaan, keuangan, kepegawaian dan pembukaan program studi agama IAIN berada di bawah tanggung jawab Departemen Agama, sedangkan dari segi pengembangan akademik khususnya bidang studi umum, berada di bawah tanggung jawab Departemen Pendidikan Nasional. Dengan SKB tersebut, maka tahapan perubahan IAIN menjadi UIN selanjutnya dilakukan melalui keputusan Presiden Republik Indonesia. (Noor, 2018).

Perubahan itu terjadi pada masa Menteri Agama yang dijabat oleh Prof. Said Agil Husein al-Munawar, dan Menteri Pendidikan Nasional ketika itu adalah Abdul Malik Fadjar, dan disahkan oleh Presiden Megawati Soekarno Putri. Khusus untuk Abdul Malik Fadjar menjadi Mendiknas yang sangat pro aktif dalam realisasi perubahan IAIN menjadi UIN, ia sangat 
Hikmah, Vol. 18, No. 2, Juli-Desember 2021， p-ISSN: 1829-8419 e-ISSN: 2720-9040

mendukunga adanya UIN sebagai basis integrasi keilmuan. (El Fiah, 2011).

Di Antara alasan yang dikemukakan oleh Azyumardi Azra dalam proposal pengajuan perubahan IAIN ke UIN sebagai berikut:

1. Untuk memberikan peluang mendapatkan pendidikan tinggi yang lebih luas kepada para tamatan madrasah.

2. Agar tamatan UIN dapat memasuki dunia lapangan yang lebih luas.

3. Agar UIN dapat menampung tamatan Madrasah Aliyah yang keadaannya sudah berubah menjadi Sekolah Menengah Umum (SMU) yang bercorak keagamaan.

4. Untuk meningkatkan martabat perguruan tinggi Islam yang berada di bawah Departemen Agama sehingga sejajar dengan martabat perguruan umum yang berada di bawah naungan Departemen Pendidikan Nasional.

Secara umum jika diringkas maka perubahan IAIN menjadi UIN menurut Amiruddin dapat dilihat dari beberapa argumentasi yakni:

- Argumentasi Politik, kebijakan pemerintah yang ada pada saat itu di bawah kepemimpinan Abdul Malik Fadjar sebagai Mendiknas memberikan peluang besar demi terwujudnya perubahan tersebu

- Argumentsi Sosial ideologis, mayoritas beragama Islam, tentu kebutuhan terhadap lembaga pendidikan pendidikan tinggi
Islam sangat diharapkan kehadirannya

- Argumentasi Dunia kerja PTKIN dalam pengembangan keilmuan harus berbasis kepada peningkatan kualitas dan keterampilan mahasiswa, sehingga lulusan dari PTKIN dapat terserap dalam semua sektor publik

- Argumentasi Keilmuan, keinginan pada integrasi keilmuan memang menjadi harapan perubahan tersebu

- Argumentasi Kompetisi global, Dengan semakin terbukanya Indonesia dalam proses globalisasi, maka tidak terhindar adanya persaingan yang terbuka. Untuk mampu bersaing maka umat Islam harus memiliki lembaga yang dapat membentuk kompetensi secara universal.

\section{INTEGRASI KEILMUAN UIN}

Perubahan dari satu bentuk lembaga ke bentuk lembaga lain tentu melahirkan karekteristik yang berbeda-beda. Di bawah ini akan dikemukakan karekteristik UIN:

1. UIN tidak mengajarkan keilmuan agama, akan tetapi juga menawarkan ilmu umum

Ada hal menarik dicermati dari perjalanan sejarah Visi Akademik PTI di atas. Pada proses awal, terutama ketika STI, maka Visi Akademik mencakup dua hal: ilmu dan agama (science and religion) atau ilmu agama dan ilmu umum (religious and seculer sciences), walau dalam praktiknya, 
ilmu agama lebih dominan karena berorientasi ke Fakultas Ushuluddin Universitas Al-Azhar. Setelah STI menjadi UII, maka ada sedikit pergeseran, jika semula penekanannya pada ilmu agama kemudian berubah penekanannya pada ilmu umum. Setelah itu, terutama setelah berdirinya PTAIN dan ADIA dan kemudian menjadi IAIN, maka Visi Akademik lebih terfokus pada pengembangan ilmu agama. Bahkan secara tegas disebutkan bahwa agama tersebut diarahkan seperti yang terdapat pada Universitas Al-Azhar, KairoMesir. Dan sejak itu pula kemudian dikenal bahwa PTI mengkhususkan kajiannya pada ilmu agama (dalam arti sempit) dan sekaligus menjadi bagian atau di bawah naungan Departemen Agama. Sedangkan Perguruan Tinggi Umum (seperti UGM) berada di bawah naungan Departemen Pendidikan. Dengan kata lain, dikhotomi ilmu agama dan ilmu umum terefleksi juga dengan adanya Departemen Agama dan Departemen Pendidikan, dan inilah fenomena umum di hampir seluruh dunia Islam sejak masa penjajahan Barat. Sebagai sebuah lembaga Universitas, UIN tidak lagi seperti IAIN, di dalamnya bukan hanya menekuni ilmu agama tetapi juga ilmu umum. Prodi-Prodi ilmu agama berada di bawah naungan Departemen Agama, sementara Prodi-Prodi umum berada di bawah naungan Departemen Pendidikan Nasional. (Darda, 2016).

2. Integrasi keilmuan sebagai respon terhadap paradigm dikotomis

Dikhotomi pendidikan agama dan umum di Indonesia yang terjadi pada masa sebelum dan awal kemerdekaan, berakibat kurangnya perhatian lembaga pendidikan Islam terhadap ilmu umum terutama sains dan teknologi. Akibatnya, umat Islam terbelakang dalam penguasaan ilmu-ilmu tersebut. Hal ini mendorong lahirnya upaya menciptakan sistem pendidikan Islam yang tidak dikhotomistik. Praktik pendidikan di IAIN juga dituding dikotomi, sebab hanya mengajarkan kelimuan agama saja. Universitas mengharuskan untuk mempelajari keilmuan umum.

Setiap UIN tentunya memiliki model integrase keilmuannya masing-masing, sebagai contoh di bawah ini akan dikemukakan integrasi keilmuan khas dari beberapa UIN di Indonesia:

a. UIn Syarif Hidayatullah UIN Syarif Hidayatullah mengusung konsep Reintegrasi Ilmu, UIN Syarif Hidayatullah memahami integrasi ilmu sebagai penyatuan ilmu keagamaan Islam dan ilmu-ilmu lain, sehingga ilmu-ilmu tersebut tidak saling bertentangan dan dikotomis.

b. UIN Sunan Ampel Surabaya UIN Sunan Ampel Surabaya mengusung konsep integrated twin towers (ITT) sebagai pengembangan keilmuannya. Simbol dua menara yang mengindikasikan bahwa masingmasing ilmu-ilmu keislaman dan sains memiliki landasan yang dapat berkembang sesuai dengan karakteristik dan objeknya masing-masing. Meskipun keduanya memiliki keunikannya masing-masing keduanya masih 
Hikmah, Vol. 18, No. 2, Juli-Desember 2021， p-ISSN: 1829-8419 e-ISSN: 2720-9040

bisa saling menyapa, bertemu dan mengaitkan diri antara satu dan lain sehingga terjadi sebuah hubungan yang harmoni. Dengan kata lain, masing-masing ilmu tidak perlu dileburkan menjadi satu namun dibiarkan berkembang dan mengembangkan diri namun harus mampu untuk saling menjembatani dan menyapa sehingga tidak ada 'kecurigaan' namun yang tercipta adalah sebuah kreativitas dan kekayaan intelektual.

c. UIN Sunan Kalijaga mengusung konsep Integrasi Interkoneksi.

Konsep ini dimaknasi sebagai ilmu yang saling terhubung satu sama lain. Ilmu-ilmu agama (islam) dipertemukan dengan ilmu-ilmu sains-teknologi, atau ilmu-ilmu agama (islam) dipertemukan dengan ilmu-ilmu sosial-humaniora, atau ilmu-ilmu sainsteknologi dipertemukan denagan ilmu-ilmu sosial humaniora.

d. UIN Sumatera Utara mengusung Konsep Wahdatul Ulum

Wahdatul 'Ulûm merupakan landasan filosofi dalam memandang kesatuan gugusan ilmu pengetahuan. Integrasi sebagai strategi mereaktualisasikan Wahdatul Ulum yang sempat terdistorsi karena terjadinya dikotomi. Sementara Transdisipliner adalah pendekatan yang digunakan untuk memahami dan

mengaktualisasikan

pengembangan ilmu dan konkritisasi bagi pengembangan peradaban dan kesejahteraan umat manusia.

e. UIN Maulana Malik Ibrahim Malang

UIN Malang memiliki keunikan tersendiri dalam filosofi keilmuannya. Dengan metapfora pohon keilmuan dan kosep ulul albaab memberikan peluang bai UIN Malang untuk tampil dalam ajang mempromosikan konsep integrasi ke dunia.

3. Tidak hanya dominan pada orientasi dakwah, tetapi juga merespon masyarakat semakin kompleks

Karekteristik Keilmuan yang ada di UIN pada dasarnya tidak terlepas dari masalah yang dihadapi oleh lembaga sebelumnya yakni IAIN yakni kurikulum IAIN belum mampu merespon perkembangan IPTEK dan perubahan masyarakat yang semakin kompleks. Selama ini kerap bahwa lulusan IAIN sebagai juru dakwah dan tidak memiliki kemampuan dalam bidang pengetahuan umun dan teknologi, sehingga dengan stigma seperti itu menghambat laju pertumbuhan karir dan pekerjaan.(Lukman, 2017).

\section{Perkembangan UIN di masa kini}

\section{Perkembangan Jumlah}

Sejak tahun 2002 (berdirinya Pertama kali UIN) hingga kini Perkembanga UIN mengalami kemajuan yang sangat pesat, Dari 
Hikmah, Vol. 18, No. 2, Juli-Desember 2021, p-ISSN: 1829-8419 e-ISSN: 2720-9040

segi kuanitas, saat ini terdapat 23 UIN dari total 58 PTKIN atau sekitar $40 \%$ dari total perguruan tinggi Islam yang ada jumalh tersebut termasuk yang cukup banyak. Adapun rincinan UIN tersebut sebagai berikut:

Tabel 2. Daftar UIN sampai dengan 2021

\begin{tabular}{|c|c|c|}
\hline No & Nama UIN & Kota \\
\hline 1 & UIN Alauddin & Makasar \\
\hline 2 & UIN Antasari & Banjarmasin \\
\hline 3 & UIN Ar-Raniry & Banda Aceh \\
\hline 4 & $\begin{array}{l}\text { UIN Fatmawati } \\
\text { Sukarno }\end{array}$ & Kota Bengkulu \\
\hline 5 & UIN Imam bonjol & Padang \\
\hline 6 & UIN Mataram & Mataram \\
\hline 7 & $\begin{array}{l}\text { UIN Maulana } \\
\text { Malik Ibrahim }\end{array}$ & Malang \\
\hline 8 & $\begin{array}{l}\text { UIN K.H. Achmad } \\
\text { Siddiq }\end{array}$ & Jember \\
\hline 9 & $\begin{array}{l}\text { UIN Prof. K.H. } \\
\text { Saifuddin Zuhri }\end{array}$ & Purwokerto \\
\hline 10 & UIN Raden Fatah & Palembang \\
\hline 11 & UIN Raden Intan & $\begin{array}{l}\text { Bandar } \\
\text { Lampung }\end{array}$ \\
\hline 12 & $\begin{array}{l}\text { UIN Raden Mas } \\
\text { Said Tengah }\end{array}$ & Sukoharjo \\
\hline 13 & $\begin{array}{l}\text { UIN Sayyid Ali } \\
\text { Rahmatullah }\end{array}$ & Tulunagung \\
\hline 14 & $\begin{array}{l}\text { UIN Sultan Aji } \\
\text { Muhammad Idris }\end{array}$ & Samarinda \\
\hline 15 & $\begin{array}{l}\text { UIN Sultan } \\
\text { Maulana } \\
\text { Hasanuddin }\end{array}$ & Serang \\
\hline 16 & $\begin{array}{l}\text { UIN Sultan Syarif } \\
\text { Kasim Riau }\end{array}$ & Pekan Baru \\
\hline 17 & $\begin{array}{l}\text { UIN Sultan Thaha } \\
\text { Saifuddin }\end{array}$ & Muaro Jambi \\
\hline 18 & $\begin{array}{l}\text { UIN Sumatera } \\
\text { Utara }\end{array}$ & Medan \\
\hline
\end{tabular}

\begin{tabular}{|l|l|l|}
\hline 19 & UIN Sunan Ampel & Surabaya \\
\hline 20 & $\begin{array}{l}\text { UIN Sunan } \\
\text { Dgunung Jati }\end{array}$ & Bandung \\
\hline 21 & Uin Sunan Kalijaga & Yogyakarta \\
\hline 22 & $\begin{array}{l}\text { UIN Syarif } \\
\text { Hidayatullah }\end{array}$ & $\begin{array}{l}\text { Tanggerang } \\
\text { Selatan }\end{array}$ \\
\hline 23 & UIN Walisongo & Semarang \\
\hline
\end{tabular}

2. Perkembangan Kurikulum dalam kurikulumnya sudah memberlakukan integrasi ilmu sebagai basis kurikulumnya. Tentunya, UIN menjadi harapan semua orang, khususnya umat Islam dan bangsa Indonesia pada umumnya. UIN tidak hanya fokus pada ilmu keislamanan saja, akan tetapi ilmu pengetahuan lainnya di luar ilmu keislamanan. Sebab, tujuan UIN dilahirkan untuk mengintegrasikan ilmu yang selama ini ilmu dipandang dalam paradigma dikotomi, sehingga lulusan dari PTKIN tidak mampu menjawab kebutuhan masyarakat. Jika lulusan PTKIN terbatas geraknya, maka lulusan tersebut tidak marketable, artinya tidak dapat berkiprah dalam semua sektor dunia usaha. Karena itu, UIN adalah solusi untuk menyahuti dinamika keilmuan dan tuntutan dunia kerja. UIN merupakan model PTKIN yang ideal di era globalisasi, di mana UIN mengembangkan multi dispilin ilmu dalam konsep integrasi ilmu.

3. Perkembangan Kelembagaan Secara kelembagaan UIN merupakan perguruan tinggi di Lingkungan 
Hikmah, Vol. 18, No. 2, Juli-Desember 2021， p-ISSN: 1829-8419 e-ISSN: 2720-9040

Kementerian Agama yang berada dan di bawah tanggung jawab menteri agama. Kemudian Saat ini pembinaan teknis penyelenggaraan program pendidikan tinggi ilmu agama Islam dilakukan oleh menteri yang menyelenggarakan urusan pemerintah di bidang agama, dan oembinaan teknis program pendidikan ilmu lain dilakukan oleh menteri yang menyelenggarkan urusan pemerintahan di bidang lain. Universitas Islam menyelenggarakan pendidikan akademik dan dapat menyelenggarakan pendidikan vokasi dalam berbagai umpul ilmu pengetahuan dan /atau teknologi dan jika memenuhi syarat dapat menyelenggarkan pendidikan profesi sesuai dengan ketentuan perundangundangan.

4. Perkembangan sarana dan prasarana Saat ini Universitas Islam Negeri sudah memiliki sarana dan prasarana yang sama seperti dimiliki oleh Universitas umum. Namun letak perbedaanya sarana dan prasarana tersebut tidak semua dimiliki oleh UIN di Indonesia, ada beberapa sarana dan prasarana yang baru dimiliki beberapa UIN saja, seperti: Rumah sakit (UIN Syarif Hidayatullah), Planetarium dan Observatorium (UIN Walisongo Semarang), Perpustakaan Digital, Asrama mahasiswa bearpa Rusunawa. (Suheri, 2014).

\section{Peluang dan tantangan UIN Kedepan}

Terdapat beberapa peluang sekalikus tantangan UIN untuk perkembangannya di masa-masa mendatang di antaranya:

1. Model integrasi kurikulum berpeluang menciptakan generasi yang 'genius', sebab pada perguruan tinggi umum lazimnya mahasiwa hanya dibekali satu keilmuan saja yakni ilmu umum, sedangkan UIN membekali Mahasiswanya dengan integrase keilmuan. Harun Nasution mengungkapkan Harus diakui tidak banyak orang yang bisa menguasai keduanya secara mumpuni. Hanya orang-orang jenius saja yang bisa melakukannya.(Indra, 2016).

2. Kebutuhan Masyrakat akan lulusan yang tidak hanya memiliki cerdas akal, akan tetapi juga memiliki kecerdasan emosional dan spiritual. UIN sangat memungkinkan untuk membentuk kepribadian alumninya seperti itu. Kurikulum dan model integrase pembelajaran akan menjadi dasar dalam pembentukan kepribadian tersebut. Bahkan lingkungan yang islami juga menjadi dasar terbentuknye kepribadian tersebut.

3. Pendidikan demokratis. Haidar Putra Daulay meneyebutkan istilah itu sebagai keunggulan dari pendidikan tinggi Islam. Maksudnya pendidikan tinggi Islam memberikan kesempatan kepada siapa saja untuk mengenyam pendidikan, tidak pandang elite atau tidaknya. Sehingga tentu akan menjadi peminatan oang. 
4. Menjadi model pendidikan tinggi tinggi Islam yang ideal bagi lembaga pendidikan tinggi Islam di luar Indonesia. Sebab sebagaimana diketahui bahwa lembaga pendidikan yang ada di timur tengah kenderungan pada ilmu agama saja.

Beberapa tantangan yang dihadapi oleh universitas Islam Negeri untuk perkembangan di masa mendatang sebagai berikut:

1. Integrasi Keilmuan tidak sekedar Label

Seperti yang dikemukakan oleh Azra bahwa tantangan terbesar setelah menjadi UIN tentu bagaimana melestarikan integrasi keilmuan tersebut. Integrasi itu bukan hanya sekedar persyaratan konsep atau gagasan tetapi menjadi cita-cita yang diwujudkan dalam bentuk kegiatan. Azra menuturkan bahwa integrasi itu dapat diterapkan dalam pembelajaran dapat juga pada penelitian, dan pengabdian Masyrakat.(Amiruddin, 2016).

2. Sarana dan prasarana yang tidak memadai

Kompetisi perguruan tinggi umum dengan perguruan tinggi Islam memang tidak dapat terelakkan, sebab sumber atau calon mahasiswa yang akan direkrut berasal dari pendidikan yang sama. Namun minimnya sarana dan prasarana di UIN tentu tidak akan dilirik oleh para calon mahasiswa. Bahkan sebenarnya bukan itu saja, kurangnya sarana dan prasarana juga berdampak pada tidak memadainya kompetensi pengetahuan yang di dapat oleh mahasiswa.

3. Peralihan dominasi minat kepada prodi umum dan penurunan minat prodi agama

Tidak menutup kemungkinan ini akan terjadi, sebagai buktinya saat ini sudah terdapat beberapa prodi pada Fakultas berbasis ilmu keagamaan yang tidak lagi diminati, hal ini tampak dari sedikitnya jumlah mahasiswa. Tentu saja dasar dari UIN yakni lembaga pendidikan ilmu keagamaan harus tetap ada, dalam arti tidak boleh memudar.

4. Sistem pengelolaan berwenang yang tidak jelas

Saat ini memang dijelaskan dalam aturan pemerintah bahwa UIN di bawah tanggung jawab kementerian agama, tetapi terdapat beberapa aturan yang memang tidak sepenuhnya $100 \%$ di kelola oleh kementerian agama, seperti misalnya penerbitan Nomor Induk Dosen Nasional tetap menjadi kewenangan kemendikbudristek. Kesimpangsiuran pengelolaan justru pada akhirnya akan menjadi tantangan untuk kemajuan pada masa mendatang.

\section{SIMPULAN}

Konversi alih status dari IAIN ke UIN memang membutuhkan persyaratan yang cukup banyak, sehingga perubahan itu tidak dapat dilakukan dengan mudah begitu saja. Tidak cukup persyaratan administrasi 
Hikmah, Vol. 18, No. 2, Juli-Desember 2021， p-ISSN: 1829-8419 e-ISSN: 2720-9040

saja, akan tetapi juga persyaratan substantif.

Saat ini terdapat 23 UIN dari total 58 PTKIN atau sekitar $40 \%$ dari total perguruan tinggi Islam yang ada. Model integrasi keilmuan di UIN Syarif Hidayatullah ialah reintegrasi ilmu, UIN Sunan Ampel Surabaya konsep integrated twin towers (ITT), UIN Sumatera Utara mengusung Konsep Wahdatul Ulu, UIN Sunan Kalijaga konsep Integrasi Interkoneksi. Kurikulum UIN tidak menganggap bahwa masing-masing keilmuan terpisah melainkan satu kesatuan, yang bersumber dari Al-Quran dan Hadis. Untuk itulah yang membuatnya begitu berbeda dengan pendidikan tinggi lainnya.

\section{DAFTAR PUSTAKA}

Amiruddin. (2016). Pemikiran Pendidikan Islam Menurut Prof. Dr. Azumardi Azra, Ma. Al-Idarah: Jurnal Kependidikan Islam, 6(2).

Amiruddin, A. (2017). Dinamika Lembaga Pendidikan Tinggi Islam Di Indonesia. MIQOT: Jurnal Ilmu-Ilmu Keislaman, 4l(1), 85-98. http://dx.doi.org/10.30821/miqot.v41i1. 314

Chailani, M. I. (2019). Pemikiran Harun Nasution Tentang Pendidikan dan Relevansinya dengan Pendidikan di Era Modern. Manazhim, 1(2), 45-60. https://doi.org/10.36088/manazhim.v1i2 .207

Darda, A. (2016). Integrasi ilmu dan agama: Perkembangan konseptual di Indonesia. At-Ta'dib, 10(1), 59-74. http://dx.doi.org/10.21111/attadib.v10i1.323

Daulay, H. P. (2018). Sejarah Pertumbuhan \& Pembaruan Pendidikan Islam di
Indonesia. Kencana.

Daulay, H. P. (2019). Pendidikan Islam di Indonesia: historis dan eksistensinya. Prenada Media.

Daulay, H. P., \& Tobroni, T. (2017). Islamic Education in Indonesia: A Historical Analysis of Development and Dynamics. British Journal of Education, 5(13), 109-126.

El Fiah, R. (2011). Integrasi-interkoneksi keilmuan ala Abdul Malik Fadjar (Refleksi Wacana dan Konstruk Sejarah Pemikiran). Analisis: Jurnal Studi Keislaman, 11(2), 313-336. Rifda El Fiah, Integrasi-Interkoneksi Keilmuan Ala Abdul Malik

Fadriati, F. (2018). Proses transformasi IAIN-UIN (Analisis Historis Serta Kompleksitas Kebutuhan Kini dan Mendatang). Proceeding iain Batusangkar, 1(2), 165-174. https://ojs.iainbatusangkar.ac.id/ojs/inde x.php/proceedings/article/view/865

Hanifah, U. (2018). Islamisasi Ilmu Pengetahuan Kontemporer (Konsep Integrasi Keilmuan di UniversitasUniversitas Islam Indonesia. TADRIS: Jurnal Pendidikan Islam, 13(2), 273294.

https://doi.org/10.19105/tjpi.v13i2.1972

Hasan, I. (2016). Meninjau Ulang Kebijakan Pemerintah Bidang Pendidikan Tinggi Keagamaan Islam. Islamadina: Jurnal Pemikiran Islam, 17(2), 1-20. https://doi.org/10.30595/islamadina.v0i 0.1322

Ikhwan, A. (2016). Perguruan Tinggi Islam dan Integrasi Keilmuan Islam. AtTajdid: Jurnal Ilmu Tarbiyah, 5(2), 159-187.

http://ejournal.inismupacitan.ac.id/index .php/tajdid/article/view/18

Indra, H. (2016). Pendidikan Tinggi Islam dan Peradaban Indonesia. Al-Tahrir: Jurnal Pemikiran Islam, 16(1), 109- 
132.

https://doi.org/10.21154/al-

tahrir.v16i1.317

Lukman, F. (2017). Integrasi-Interkoneksi dalam Studi Hadis Disertasi Di Uin Sunan Kalijaga Yogyakarta. RELIGIA, $19(2)$, $1-11$. https://doi.org/10.28918/religia.v19i2.7 46

Minhaji, H. A. (2007). Masa Depan Perguruan Tinggi Islam di Indonesia (Perspektif Sejarah-Sosial). TADRIS: Jurnal Pendidikan Islam, 2(2), 64-78. https://doi.org/10.19105/tjpi.v2i2.218

Noor, W. (2018). Azyumardi Azra: Pembaruan Pemikiran dan Kelembagaan Pendidikan Islam Di Indonesia. Tarbawy: Jurnal Pendidikan Islam, 5(1), 19-28. https://doi.org/10.32923/tarbawy.v5i1.8 27

Pairin, P. (2012). Sejarah Pendidikan Perguruan Tinggi Agama Islam. Shautut Tarbiyah, 18(2), 116-141. http://dx.doi.org/10.31332/str.v18i2.79 $\% 09$

Rapono, M. (2020). UIN-IAIN-STAIN: Perkembangan Epistemologi dan Institusi Perguruan Tinggi Islam Indonesia. Tazkiya, 8(2). http://jurnaltarbiyah.uinsu.ac.id/index.p hp/tazkiya/article/view/572

Rifai, N., Fauzan, F., \& Bahrissalim, B. (2014). Integrasi Keilmuan dalam Pengembangan Kurikulum di uin seIndonesia: Evaluasi Penerapan Integrasi Keilmuan UIN dalam Kurikulum dan Proses Pembelajaran. Tarbiya: Journal of Education in Muslim Society, 1(1),
13-34.

https://repository.uinjkt.ac.id/dspace/ha ndle/123456789/31693

Suheri, S. (2014). Refleksi historis konversi STI ke UIN. Tarbiyatuna, 7(1), 1-19. https://www.iaisyarifuddin.ac.id/ejourna 1/index.php/tarbiyatuna/article/view/44

Suradi, A. (2018). Analisis Format Ideal Transformasi Institut Menuju Universitas di PTKIN. Jurnal Pendidikan Agama Islam Al-Thariqah, 3(1), 1-14. https://doi.org/10.25299/althariqah.201 8.vol3(1).1205 